\title{
PREENCHIMENTO CORRETO DA NOTA FISCAL ELETRÔNICA: COMO EVITAR TRANSTORNOS EM PEQUENAS E MÉDIAS EMPRESAS DO COMÉRCIO
}

\section{ARTIGO ORIGINAL}

SILVA NETO, Manoel dos Santos 1, FURTADO NETTO, Jethro Sampaio 2, SANTOS, Andreza Karoline dos 3, CAVALCANTE, Antônia Alderleia Pereira 4, ROBERTO, José Carlos Alves ${ }^{5}$, SERRA, Meg Rocha da Cunha ${ }^{6}$, LOPES, Nelânia Ferreira $^{7}$

SILVA NETO, Manoel dos Santos. Et al. Preenchimento correto da nota fiscal eletrônica: como evitar transtornos em pequenas e médias empresas do comércio. Revista Científica Multidisciplinar Núcleo do Conhecimento. Ano. 06, Ed. 11, Vol. 04, pp. 177-201. Novembro 2021. ISSN: 2448-0959, Link de

${ }^{1}$ Graduanda do curso de Ciências Contábeis.

2 Graduando do curso de Contabilidade.

${ }^{3}$ Graduando do curso de contabilidade.

${ }^{4}$ Graduando do curso de contabilidade.

5 Orientador. Mestre em Engenharia de produção. Especialista Logística empresarial. Graduado em Administração com Ênfase em Marketing.

6 Orientadora. Mestra em Engenharia de Processos Industriais pela UFPA , especialista em Controladoria e Auditoria Contábil pelo Ciesa, Graduada em Ciências Contábeis pelo Centro Universitário do Norte. Graduada em Ciências Econômicas pelo Centro Universitário do Norte.

7 Orientadora. Especialista em Auditoria Contábil, Financeira e Tributaria e Graduada em Ciências Contábeis.

$\mathrm{RC}: 100828$

Disponível em: https://www.nucleodoconhecimento.com.br/contabilidade/preenchimentocorreto 
acesso: https://www.nucleodoconhecimento.com.br/contabilidade/preenchimentocorreto

\section{RESUMO}

Perante o cenário de globalização no qual estamos inseridos, as inovações vêm sucedendo em todos os campos, fazendo com que as organizações tenham que trabalhar e tomar decisões em um ritmo mais acelerado do que se tomava. No setor da contabilidade, o governo optou, também, por modernizar seus processos e controles, estabelecendo, para isso, a emissão de Notas Fiscais de forma eletrônica. Contudo, erros na Nota Fiscal Eletrônica podem gerar problemas fiscais e originar impactos financeiros expressivos no negócio. Assim, tem-se como problema de pesquisa: Como é possível evitar os transtornos relacionados ao preenchimento incorreto de Nota Fiscal Eletrônica em empresas de pequeno e médio porte do setor do comércio? Desta forma, o objetivo geral deste artigo é: Compreender a importância do preenchimento correto da Nota Fiscal Eletrônica na fluência de informações entre as partes envolvidas nos processos de empresas de pequeno e médio porte no setor do comércio. Para alcançá-los, realizou-se uma revisão de literatura, partindo de uma pesquisa qualitativa e descritiva. Concluiu-se que, por se tratar de um processo trabalhoso, preencher todos os dados da Nota Fiscal Eletrônica pode ocasionar vários problemas em sua emissão, seja por falha de digitação, esquecimento ou erro no próprio sistema das prefeituras. Assim, para que não se tenha grandes problemas, é preciso que a empresa tenha um sistema de emissão de Nota Fiscal Eletrônica que automatize de maneira inteligente este trabalho, impedindo, assim, as falhas humanas, assegurando todo o suporte que a empresa necessita.

Palavras-chaves: Contabilidade, Fraudes fiscais, Nota fiscal eletrônica, NF-e.

RC: 100828

Disponível em: https://www.nucleodoconhecimento.com.br/contabilidade/preenchimentocorreto 


\section{INTRODUÇÃO}

Perante o cenário de globalização no qual estamos inseridos, as inovações vêm sucedendo em todos os campos, fazendo com que as organizações tenham que trabalhar e tomar decisões em um ritmo mais acelerado do que se tomava há tempos. Neste contexto, o uso de meios eletrônicos tornou-se parte imprescindível para as organizações de micro, pequeno, médio e grande porte. No setor da contabilidade, esse processo de informatização surgiu, especialmente, com a fundação do projeto Sistema Público de Escrituração Digital (SPED), com o intuito de padronizar e compartilhar informações contábeis e fiscais, formado por três grandes subprojetos: Escrituração Contábil Digital (ECF), Escrituração Fiscal Digital (EFD) e a Nota Fiscal Eletrônica (NF-e).

Com o progresso das tecnologias, o governo optou, também, por modernizar seus processos e controle, estabelecendo a emissão de Notas Fiscais de forma eletrônica. Trata-se de um processo relativamente simples, contudo, demanda atenção e cuidado por parte do empresário. Destaca-se que erros na NF-e podem gerar problemas fiscais e originar impactos financeiros expressivos no negócio. Desta forma, tem-se como objetivo deste artigo: Compreender a importância do preenchimento correto da Nota Fiscal Eletrônica (NF-e) na fluência de informações entre as partes envolvidas nos processos de empresas de pequeno e médio porte no setor do comércio. Assim, tem-se como problema de pesquisa: Como é possível evitar transtornos relacionados ao preenchimento incorreto de Nota Fiscal Eletrônica em empresas de pequeno e médio porte do setor do comércio?

Para desenvolver este estudo, realizou-se uma pesquisa bibliográfica, a partir da literatura publicada em meios virtuais, pesquisas por meio de leis, manuais e artigos de revistas, com publicações dos últimos 10 anos, para o recorte temporal. Tratouse de uma pesquisa descritiva, de caráter qualitativo. De tal modo, as questões

RC: 100828

Disponível em: https://www.nucleodoconhecimento.com.br/contabilidade/preenchimentocorreto 
norteadoras desta pesquisa estão baseadas nos seguintes objetivos específicos: apresentar a importância da NF-e para o planejamento da empresa e os impactos de sua implantação; demonstrar a necessidade de detectar e impedir falhas no preenchimento da NF-e; entender a necessidade de manter os dados atualizados para o preenchimento das notas fiscais; e identificar os principais entraves encontrados pelas empresas de pequeno e médio porte no que diz respeito à implantação da NF-e.

Assim sendo, diante do exposto nesta introdução e que será discutido ao longo do artigo, será evidenciada a importância do preenchimento correto da NF-e nas organizações, já que se parte do pressuposto de que o empresário que está em harmonia com o governo tem um plano financeiro bem arquitetado, ou seja, um maior controle de seu patrimônio e do que é emitido, possuindo, também, a capacidade de conseguir melhores resultados e assegurar a sobrevivência da empresa no mercado. Desta forma, o preenchimento incorreto de uma informação na nota fiscal eletrônica pode ocasionar muitos transtornos à empresa, uma vez que, além do cliente não aceitar a nota fiscal e a empresa correr o risco de não conseguir o cancelamento deste documento, existe a possibilidade de a empresa ser autuada em uma eventual fiscalização.

\section{REFERENCIAL TEÓRICO}

De acordo com Lakatos e Marconi (2010), todo estudo científico precisa ser baseado por um referencial teórico, em que se tem a citação das principais conclusões de autores a respeito da temática em questão, colaborando para a produção da pesquisa desenvolvida.

RC: 100828

Disponível em: https://www.nucleodoconhecimento.com.br/contabilidade/preenchimentocorreto 


\subsection{EMPRESAS COMERCIAIS DE PEQUENO E MÉDIO PORTE}

As empresas são classificadas, a partir da Pesquisa de Inovação Tecnológica (PINTEC) de 2011, publicada pelo Instituto Brasileiro de Geografia e Estatística (IBGE), de acordo com seu porte, em três grupos: micro e pequenas, médias e grandes (NOGUEIRA; ZUCOLOTO, 2017), como pode ser visto na Figura 1, a seguir.

Figura 1: Definição de porte de estabelecimentos segundo o número de empregados

\begin{tabular}{l|c|c} 
Porte & Comércio e Serviços & Indústria \\
\hline Microempresa (ME) & Até 9 empregados & Até 19 empregados \\
\hline Empresa de Pequeno Porte (EPP) & De 10 a 49 empregados & De 20 a 99 empregados \\
\hline Empresa de médio porte & De 50 a 99 empregados & De 100 a 499 empregados \\
\hline Grandes empresas & 100 ou mais empregados & 500 ou mais empregados \\
\hline
\end{tabular}

Fonte: SEBRAE (2013)

\subsection{A TECNOLOGIA}

Segundo Bufrem et al. (2018), a tecnologia é o aproveitamento da ciência científica junto às características da matéria e da energia para que possam ser elaborados novos produtos e métodos direcionados, com o intuito de diminuir o empenho humano. Diegues et al. (2019), destacam que a tecnologia não é sempre e basicamente um resultado da ciência, podendo se adiantar e, inclusive, agregar contribuições ao estudo científico, pois, muitas vezes, uma grande necessidade da humanidade obriga o surgimento de uma tecnologia, como, por exemplo, da

RC: 100828

Disponível em: https://www.nucleodoconhecimento.com.br/contabilidade/preenchimentocorreto 
máquina a vapor, ao mesmo tempo em que a execução de uma tecnologia abastece a pesquisa científica com informações.

Dentre os progressos tecnológicos, têm-se as novas mídias eletrônicas, destacadas pelo emprego dos computadores, das redes e, sobretudo, da Internet. Diante desse cenário, concebe-se que a tecnologia digital possibilitou juntar no computador todas as outras mídias que antes eram executadas em separado: a escrita, a música e o som, tabelas, o filme, a animação, os gráficos e o programa de computador. Essas mídias adicionadas à interação se transformaram em algo novo, com grande potencial (SENA et al., 2019).

\subsubsection{SISTEMA DE GESTÃO DE INFORMAÇÃO}

Define-se a informação, especialmente na sociedade contemporânea, como sendo uma mensagem de comunicação que pode ser ouvida ou vista, geralmente exposta no formato de documento, que abrange um emitente e um receptor, com a intenção de alterar a forma como o destinatário observa algo ou cumprir algum resultado sobre sua análise e desempenho. De forma diferente dos dados, a informação possui significado e se organiza para uma finalidade (MONTEIRO; DUARTE, 2018). Há poucos anos, havia um clima menos incerto, em que tudo era processado de forma bem lenta, contudo, após o começo dos anos 90, novos acontecimentos, como a abertura aos produtos estrangeiros, concorrentes mais enérgicos, fornecedores mais fortes e clientes mais exigentes, fizeram com que o mercado ficasse mais dinâmico e agressivo, assim como tornou-se muito mais competitivo.

A fim de garantir a continuação e os lucros, as empresas optaram por seguir uma estratégia nova, amparada na consistência na informação, assim entendida como um capital estratégico que permitia às organizações conhecerem seu próprio espaço, mercados, consumidores e concorrentes (GAZZOLA; WOIDA, 2019). Os mercados tornaram-se sofisticados e foi preciso aprimorar os setores de informação RC: 100828

Disponível em: https://www.nucleodoconhecimento.com.br/contabilidade/preenchimentocorreto 
das organizações, adicionando estratégias para alcançar progresso. Assim, a informação tornou-se alicerce para a competição, tendo a capacidade de ativar as opções tecnológicas para o seu controle e administração (CÂNDIDO, 2017). Cândido (2017) afirma que a organização precisa ter conhecimento de que a informação é uma condição tão necessária quanto os recursos humanos, já que é dela que é condicionado o progresso ou o fracasso das decisões tomadas por seus responsáveis e, ainda, por todos os seus colaboradores.

Assim, diante do cenário apresentado, pode-se definir a informação como um item essencial às organizações, sendo possível determinar as condições indispensáveis para alcançar seus objetivos e elevar a competitividade. Destaca-se, ainda, que se deve levar em conta que a estratégia sempre se configura baseada nas informações dispostas e que, por conta disso, não há estratégia melhor do que a informação da qual procede. Portanto, o que definirá a nobreza de uma organização será a capacidade de colher, aparelhar, avaliar e praticar alterações a partir de informações, agregando-as no processo de melhoria contínua de suas ações (BELLUZZO, 2017). A informação é essencial no suporte às estratégias e aos processos de tomada de decisão, conforme Ottonicar et al. (2017), pois permite um maior controle das atividades da empresa.

Os autores ainda complementam afirmando que usar a informação consiste em intervir na gestão, sendo possível gerar uma transformação organizacional, já que este uso impactaria nos vários itens que formam tal sistema. Assim, a gestão consiste em um grupo de processos que compreendem ações de planejamento, aparelhamento, comando, repartição e controle de recursos de qualquer natureza, visando à racionalização e à efetividade do apontado sistema, produto ou serviço (SOUZA et al., 2011). No ponto de vista da gestão da informação, deve-se adicionar, em dimensões estratégicas e operacionais, métodos para alcançar e usar recursos humanos, tecnológicos, financeiros, materiais e físicos para o controle da própria

RC: 100828

Disponível em: https://www.nucleodoconhecimento.com.br/contabilidade/preenchimentocorreto 
informação, que logo precisa ser disposta como insumo favorável e estratégico para sujeitos, grupos e empresas (SOUZA et al., 2011).

Amorim e Tomael (2011) afirmam que a gestão da informação abrange a sinergia entre a tecnologia da informação, comunicação e os recursos/conteúdos informativos, buscando a implementação de estratégias e a determinação de atividades empresariais. Assim sendo, a gestão da informação sugere mapear as informações indispensáveis, realizar sua coleta, analisar sua qualidade, resultar no seu armazenamento e à sua repartição e seguir os resultados de seu emprego. Gestão estratégica da informação consiste no emprego da informação para objetivos estratégicos a fim de alcançar vantagem competitiva (RODRIGUES; BLATTMANN, 2014). A partir de uma avaliação do panorama em que as organizações estão incluídas, pode-se verificar o quanto a agitação deste as pressiona, fazendo com que estas empresas interajam com um ambiente em frequente transformação, que apresenta tanto conveniências quanto ameaças (SANTOS; VALENTIM, 2014).

\subsubsection{SISTEMAS ERP}

Os sistemas ERP, Enterprise Resource Planning ou Planejamento dos Recursos da Empresa, são sistemas de informação interligados obtidos no formato de pacotes comerciais de software buscando ajudar à maioria das atividades de uma organização (FERNANDES et al., 2017). Levando em conta o modelo da cadeia de valor, compreende-se que os sistemas ERP buscam garantir a eficiência nas atividades organizacionais que admitem desde a logística de entrada até as pertinentes à logística de saída e parte das ações de marketing e vendas (ALMEIDA, 2016). Embora as organizações tenham desenvolvido sistemas internos com as mesmas propriedades, o ERP está, frequentemente, ligado a pacotes comerciais. Sendo uma propriedade relevante dos ERP o fato de que pelo seu desenvolvimento

RC: 100828

Disponível em: https://www.nucleodoconhecimento.com.br/contabilidade/preenchimentocorreto 
ser de maneira genérica para acatar a vários clientes, eles congregam modelos e métodos de negócios ("best-practices") (ALMEIDA, 2016).

Quando uma empresa decide pelo uso dos sistemas ERP, elas esperam alcançar múltiplos benefícios, dentre eles: a conexão entre as várias operações da cadeia de valor, o acréscimo das possibilidades de gerenciamento dos processos organizacionais, a modernização tecnológica, a diminuição de custos de informática e o contato com informações de qualidade em tempo real para a tomada de decisões a respeito de toda a cadeia produtiva (ANZILAGO et al., 2017). Contudo, há problemas que devem ser levados em conta, como: dependência do fornecedor, tempo de aprendizagem, oposição a mudanças, custos e prazos de prática, e outros (ANZILAGO et al., 2017). Como os sistemas ERP são conectados, ou seja, trata-se de um único sistema que ajuda a todas as operações da cadeia de valores da organização, é uma propriedade muito relevante.

Um problema relativo à integração é que os sistemas ERP conferem uma visão de processos àquelas organizações que os executam, forçando-as a entender e atravessar seus obstáculos (ALMEIDA, 2016). Por fim, verifica-se que os sistemas ERP ocasionaram vantagens relacionadas à consistência das atividades internas da organização, possibilitando diminuição em estoques de matérias primas, diminuição em tempos de recepção de pedidos, fabricação e recebimento e, ainda, de ganhos de eficiência pela supressão de atividades desenvolvidas de forma manual (FERNANDES et al., 2017).

\subsection{NA CONTABILIDADE}

Com o progresso da tecnologia, não apenas a contabilidade precisou se adaptar por conta do processo de informatização dos dados, mas também o contador, para transmitir os dados para a Receita Federal do Brasil, para os municípios e para o Estado (SOUZA et al., 2017). São diversas obrigações secundárias federais, RC: 100828

Disponível em: https://www.nucleodoconhecimento.com.br/contabilidade/preenchimentocorreto 
estaduais e municipais a serem compartilhadas pelos contribuintes, dentre elas temse: DCTF, DACON, DIPJ, DIME, SINTEGRA e, hoje em dia, o Sped Contábil e o Sped Fiscal. Prontamente, depois do envio dos dados, estes já podem ser acessados pelos órgãos de fiscalização competentes (ORIGUELA, 2017). Neste momento de transformação de processos, tem-se o período de aprendizagem e inovação dos contadores, sendo que a necessidade de alterar os antigos processos surgiu não apenas com a NF-e e com a escrituração digital, mas ainda com a era da informática, sendo que não se aceita procedimentos de escrituração contábil desenvolvidos à mão.

É demandado dos profissionais mais que habilidade técnica: é indispensável que estejam aptos às transformações, quaisquer que sejam as suas especificações (RUSCHEL; FREZZA; UTZIG, 2011). Desta forma, a informática chega para cooperar no trabalho em geral tanto do contador, do fisco e até do empresário, com a implantação da NF-e. Sobre a NF-e, Bicca e Monser (2020), afirmam que as informações da nota fiscal que o empresário emitiu poderão ser acessadas e visualizadas por meio do visualizador elaborado pela Receita Federal do Brasil e disponível para download no Portal Nacional da NF-e a partir da chave de acesso da nota. As informações da NF-e impressas em papel possuem a função somente de conduzir as mercadorias, não sendo mais indispensável a emissão do documento em quatro vias, em formulário previamente autorizado pelo fisco estadual.

Desta forma, o fisco tem, em tempo real, as informações da NF-e (BONFIM, 2012). Para o contador, reduziu o volume de papel e a burocracia. Atualmente, com a NF-e, não é mandatória a digitação da nota. Somente com o arquivo XML pode-se importar os dados para o sistema de escrituração contábil-fiscal. Os comprometimentos acessórios, como o SINTEGRA, e a emissão dos livros fiscais e contábeis estão sendo trocados gradualmente pelo Sped Fiscal e Contábil, 
atenuando, assim, uma das obrigações funcionais do contador (ANDRADE; MEHLECKE, 2020).

\subsubsection{ESCRITURAÇÃO CONTÁBIL}

Conforme o Conselho Federal de Contabilidade (CFC), a escrituração contábil é mandatória para a totalidade das empresas, até mesmo para as micro e pequenas empresas. Após a aprovação da Resolução CFC № 1.330/11, os contadores estão forçados a executar a Interpretação Técnica Geral (ITG) 2000. No segundo item desta, define-se que ela precisa ser abraçada para todas as empresas, sem importar sua natureza e seu porte, no desenvolvimento da escrituração contábil, notadas as cobranças da legislação e de outras normas cultiváveis, se houver (ITG, 2011). A Lei de № 10.406, de 2002 (Novo Código Civil), em seu Art. 1.179, ainda prevê a escrituração contábil como obrigatória (BRASIL, 2002). Trata-se de uma técnica contábil fundamentada em desenvolver os carecidos registros nos Livros-Diários, Razão e Caixa, cuja mudança ou fato na organização que mudem a sua situação patrimonial, deve ser registrada.

Seu surgimento veio da necessidade de controlar o patrimônio e conservar todos os registros indispensáveis para o bom desempenho da organização (RODRIGUES; JACINTO, 2011). Trata-se, ainda, do registro cronológico e específico da natureza de todos os acontecimentos que sucedem a organização. Tem-se a obrigação por parte dos empresários de manter o sistema de escrituração contábil aceitável, onde, anualmente, é necessário demonstrar os balanços patrimoniais e de resultado econômico. Esta ação é muito importante, sendo que a legislação qualifica como crime a escrituração de maneira irregular, caso constatada a falência do empresário (BRASIL, 2005). Apesar de a Lei tratar apenas das escriturações em livros, há outros tipos de ferramentas de escrituração, podendo ser conjuntos de fichas ou

RC: 100828

Disponível em: https://www.nucleodoconhecimento.com.br/contabilidade/preenchimentocorreto 
folhas soltas, folhas contínuas, microfichas retiradas a partir de microfilmagem por computador (TOMELIN et al., 2010).

A Lei assinala que o único livro hoje em dia indispensável a todo empresário é o livro-diário, que pode ser elaborado a partir de fichas, em situações de escrituração mecanizada ou eletrônica. Este livro pode ser trocado pelo livro de balancetes diários e balanços, em caso de se seguir o sistema de fichas de lançamentos (TOMELIN et al., 2010). Assim, o livro-diário é o único obrigatório, sendo permitidos os livros-caixa com controles de entradas e saídas de caixa, estoque, razão, que são consideradas todas as mudanças das mercadorias. Há, ainda, o rascunho do livrodiário, que é o borrador e, por fim, a conta corrente, sendo usada para contas de fornecedores e clientes singulares (BATISTA et al., 2017).

\subsection{CONCEITO DE NOTA FISCAL}

De acordo com Pereira (2019), menciona-se que a nota fiscal é um documento fiscal com o intuito de registrar uma transferência de propriedade sobre um bem ou uma ação comercial realizada por uma empresa a uma pessoa física ou outra empresa. A Nota Fiscal é um apontamento bem mais elaborado que o Cupom Fiscal, contendo dados mais minuciosos, como informações fiscais da entidade, tributação, frete, informações pessoais do consumidor etc. Ela é importante para conservar a regularização da organização, assegurar os direitos do consumidor, colher tributos e muitos outros.

Nas circunstâncias em que a Nota Fiscal faz o registro da transferência de valor monetário entre ambos, ela ainda se direciona a coleta de impostos e a falta do seu uso qualifica a sonegação fiscal. Contudo, elas podem, ainda, ser empregadas em conjunturas mais abrangentes, regularizando doações, transporte de bens, empréstimos de bens ou prestação de serviços sem vantagem financeira à organização emissora. Ela pode, ainda, invalidar a validade de outra Nota Fiscal, RC: 100828

Disponível em: https://www.nucleodoconhecimento.com.br/contabilidade/preenchimentocorreto 
como no caso da restituição de produtos de natureza industrial, outras anulações ou anulações contratuais de serviços e produtos (MACHADO et al., 2016).

\subsubsection{NOTA FISCAL ELETRÔNICA}

A NF-e é conferida por Lei para contribuintes por decisão do fisco, que estabelece limites para a adoção. Seu uso pode auxiliar o Estado no comando tributário, com um quantitativo sempre maior de movimentações comerciais. Existe, ainda, o aumento do custo para a vigilância e precaução da fuga tributária (PEREIRA, 2019). A NF-e já é uma realidade desde outubro de 2005, com a aprovação do Ajuste SINIEF 07/05, que estabeleceu nacionalmente a NF-e e o Documento Auxiliar da NF-e - DANFE (ANDRADE; MEHLECKE, 2020). NF-e é conceituado como o documento enunciado e guardado de forma eletrônica para documentar operações e prestações agenciadas pelo contribuinte, de existência somente digital, com validade jurídica assegurada por assinatura digital do emitente e autorização de uso munida pela Secretaria de Estado da Fazenda antes do acontecimento do fato gerador (ALENCAR; FRANÇA, 2020).

A NF-e oferece transparência no relacionamento com o fisco e diminuição de custos com a impressão de relatórios em papel. O seu envio torna dispensável a Autorização para a Impressão De Documentos Fiscais (AIDF) e auxilia na padronização do procedimento de envio de nota fiscal em todos os Estados e o DF (ALENCAR; FRANÇA, 2020). Segundo a Receita Federal do Brasil em Guia Prático da Escrituração Fiscal Digital (EFD), o projeto ainda permite benefícios e vantagens às partes envolvidas, como: aumento na credibilidade da Nota Fiscal; Melhoramento no procedimento de controle fiscal, permitindo uma troca melhor e repartição de dados entre os fiscos; Diminuição de custos no procedimento de gerenciamento das notas fiscais apanhadas pela fiscalização de mercancías em trânsito; Redução da sonegação e ampliação da arrecadação; e Ajuda nos planos de escrituração

RC: 100828

Disponível em: https://www.nucleodoconhecimento.com.br/contabilidade/preenchimentocorreto 
eletrônica contábil e fiscal da Receita Federal e outras Secretarias de Fazendas Estaduais.

Promove, ainda, dentre os outros benefícios descritos no parágrafo anterior, o fortalecimento da conexão entre os fiscos, fortalecendo a fiscalização desenvolvida pelas Administrações Tributárias por conta do compartilhamento das informações das NF-e; Aceleração no acesso às informações; Supressão do papel; Aumento da produtividade da auditoria por meio da abolição dos passos para coleta dos arquivos; e Possibilidade do encontro de informações por meio eletrônico (AGUIAR; GOUVEIA, 2019; APARECIDO, 2021; SANTOS, 2017). Depois do credenciamento e do certificado digital, a organização deve escolher qual programa será empregado para envio da NF-e. No Portal da NF-e, a entidade emissora tem a alternativa de desenvolver sistema próprio, comprar no mercado especializado, contratar Serviço sob demanda, ou usar do Emissor Gratuito dos Estados: versão de teste e versão de produção (BARBOSA et al., 2018).

Percebe-se que a empresa não essencialmente necessita ter gastos com a implantação da NF-e em relação ao programa, já que o Portal da NF-e oferece a alternativa de utilizar o programa de emissor gratuito. Contudo, o que falta nas organizações não são apenas recursos financeiros para a implantação, mas medidas que auxiliam o processo do envio da NF-e. A NF-e apareceu para favorecer usuários como os contribuintes, a sociedade e o governo. Entretanto, se esta ferramenta de melhoramentos não for executada de forma educativa, não existirá resultados efetivos.

\subsubsection{PROJETO DA NOTA FISCAL ELETRÔNICA}

O projeto da nota fiscal eletrônica iniciou com $01^{\circ}$ Encontro Nacional de Administradores Tributários (ENAT), realizado em julho de 2004, em Salvador (BONFIM et al., 2012). De acordo com o portal da NF-e, este projeto tem a finalidade RC: 100828

Disponível em: https://www.nucleodoconhecimento.com.br/contabilidade/preenchimentocorreto 
de inserir um padrão nacional de apontamento fiscal de forma eletrônica que possa substituir a sistematização contemporânea de emissão da NF em forma de papel, com legitimidade jurídica assegurada pela assinatura remetente de modo digital. Assim, simplifica-se todas as obrigações caracterizadas como acessórias dos contribuintes e possibilita, simultaneamente, o acompanhamento em tempo real das intervenções mercantis pelo Fisco (VIEIRA et al., 2019). Trata-se de um grande progresso para promover as ações tanto do contribuinte como as operações de fiscalização a respeito das ações e prestações sobre o ICMS e IPI (VIEIRA et al., 2019).

\subsubsection{A JUSTIFICATIVA PARA A EXECUÇÃO DA NF-E}

Tem-se como justificativa para a concepção do projeto e cumprimento da NF-e, alguns pressupostos:

a) As administrações tributárias encaram o amplo desafio de ajustarem-se ao avanço de tecnologias e ao processo de informatização do comércio e das movimentações entre contribuintes. As quantidades de movimentações executadas e os montantes de recursos mobilizados acendem intensamente e, na mesma magnitude, ampliam-se os custos intrínsecos à necessidade do Estado de identificar e precaver a fuga tributária;

b) Em relação às administrações tributárias, existe a precisão de gastar grandes somatórias de recursos para capturar, discutir, registrar e dispor dados a respeito das ações desenvolvidas pelos contribuintes, gerindo um quantitativo de obrigações acessórias que segue o aparecimento de novas conjecturas de evasão;

c) De forma abrangente, o projeto tem sua justificativa garantida pela precisão de investimento público direcionado para a diminuição da papelada do comércio e dos obstáculos administrativos encarados pelos empresários do País, demandando a atualização dos controles de tributos nos três domínios de governo (OLIVEIRA, 2009).

RC: 100828

Disponível em: https://www.nucleodoconhecimento.com.br/contabilidade/preenchimento- 
O projeto justifica-se por investir em tecnologia, com o intuito de atualizar o parque tecnológico e os sistemas de informação, expandindo os atendimentos, devido, principalmente, à otimização de tempo.

\subsubsection{CARACTERÍSTICAS DA NOTA FISCAL ELETRÔNICA}

O prontuário de integração do contribuinte da NF-e determina que, juntamente com a mercadoria, haverá uma representação gráfica da nota fiscal eletrônica de forma simplificada, nomeada de Documento Auxiliar da Nota Fiscal Eletrônica (DANFE), em apenas uma via impressa em papel comum, contendo a chave de acesso e o código de barras linear, a fim de ajudar na busca da NF-e e confirmar dados pelas unidades fiscais e contribuintes destinatários (PARISOTTO; FREIRE, 2010).

DANFE é o apontamento auxiliar para busca da nota fiscal eletrônica, já que possui a chave de acesso da mesma, possibilitando que o detentor do documento acompanhe a NF-e, por meio dos sites das Secretarias de Fazenda Estaduais autorizadas ou Receita Federal.

Diante do cenário aqui apresentado, bem como da relevância notória da ferramenta para os contribuintes, uma vez que as informações, agora, podem ser obtidas de maneira mais rápida e eficaz, destaca-se que, no instante inicial da implantação do projeto, o contribuinte destinatário, não emissor de nota fiscal eletrônica, pode escriturar este apontamento, assim, sua validade fica ligada à concreta existência da nota fiscal eletrônica, com permissão de uso no Banco Dados das gerências tributárias inseridas no procedimento (BARBARIOLE et al., 2010). O processo de emissão de NF-e tem algumas características dentre as quais os profissionais das empresas que estarão envolvidos nestas áreas terão que se atualizar para entenderem o processo.

RC: 100828

Disponível em: https://www.nucleodoconhecimento.com.br/contabilidade/preenchimentocorreto 


\subsubsection{OPERACIONALIZAÇÃO DA NOTA FISCAL}

A operacionalização da NF-e não é complicada. De acordo com Pereira (2019), ocorre da seguinte forma: a organização que emite a NFe deve originar um arquivo em meio eletrônico com os dados fiscais, contendo uma assinatura digital para a segurança dos dados originados pelo emissor. $O$ arquivo eletrônico é a NF-e, emitido e enviado por meio da internet para a Secretaria da Fazenda (SEFAZ). A SEFAZ, por sua vez, faz uma pré-validação do arquivo e envia um comprovante, que se trata de um protocolo de permissão de uso e recebimento. Assim, é possível se ter a movimentação da mercadoria. A nota fiscal eletrônica é disposta pela SEFAZ para buscas na internet a quem interessar, sendo estes quem emitiu e quem irá receber, que podem conferir, por meio da chave de acesso, no site do portal da NF-e (BRASIL, 2005; TRETER et al., 2018), como se vê na Figura 2.

Figura 2: Consulta NF-e

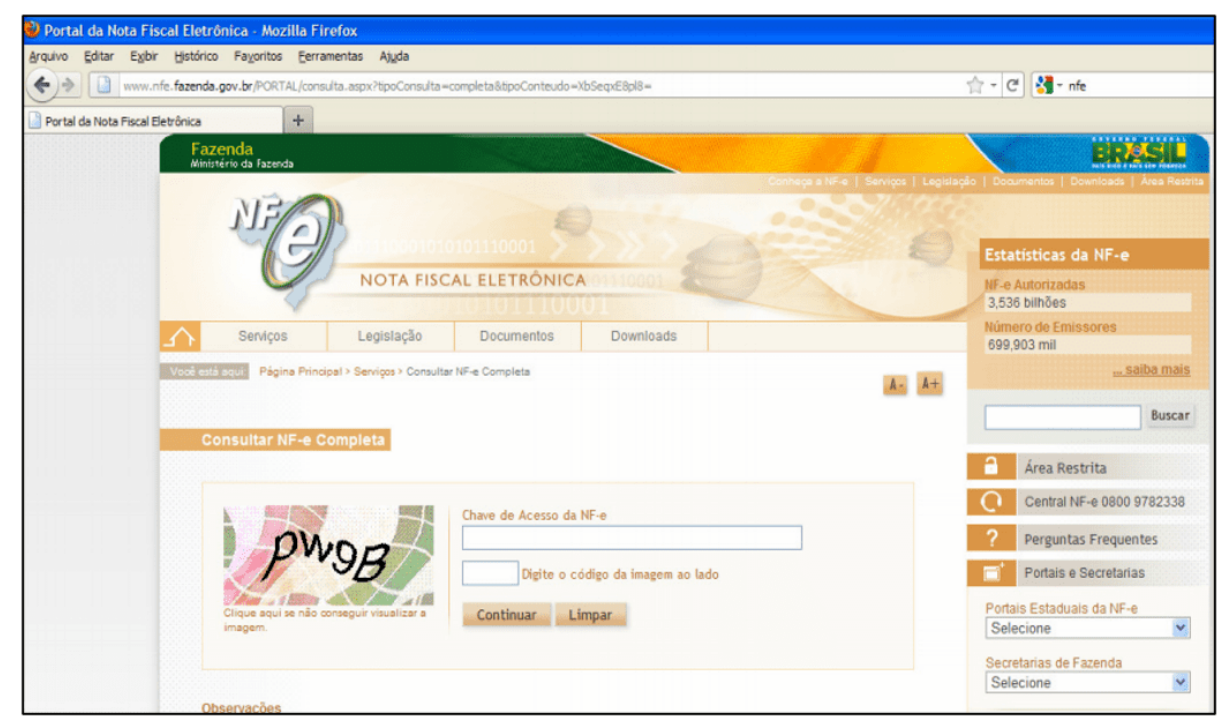

Fonte: Secretaria do Ministério da fazenda (2018)

RC: 100828

Disponível em: https://www.nucleodoconhecimento.com.br/contabilidade/preenchimento$\underline{\text { correto }}$ 
A SEFAZ faz a transmissão do arquivo à receita federal e, no caso de transação interestadual, faz-se a transmissão à Secretaria da Fazenda, destinatária da ação. Para que se tenha a movimentação da mercadoria, é preciso a impressão de uma representação da nota fiscal eletrônica, chamada DANFE, em via única de papel comum, que contém a chave de acesso e o código de barras linear para ajudar na busca da NF-e na Internet (TRETER et al., 2018). A transmissão pode ser realizada de forma individual, apenas uma NF-e, ou em lotes de NF-e. A Secretaria da Fazenda, depois de receber a NF-e via Internet, válida sua recepção automaticamente, avaliando a integridade do documento (BONFIM et al., 2012).

Caso não seja identificado nenhuma falha, a nota fiscal eletrônica é recebida e guardada pela SEFAZ que, ao mesmo tempo, voltará com um protocolo de transação com status "Autorização de Uso" e, assim, a NF-e é disposta para busca por meio da chave de acesso, no Portal da NF-e. Depois de receber o protocolo de transação, pode acontecer a saída da mercadoria, que precisa ser acompanhada do DANFE (PEREIRA, 2019). Depois do recebimento pela SEFAZ, ela transmite a nota fiscal eletrônica de origem para a Receita Federal do Brasil. Assim, no caso de ações interestaduais, os Postos Fiscais de Fronteira recebem a informação prévia da nota fiscal eletrônica, retirando a prática de digitar notas fiscais, ajudando no controle do Fisco e diminuindo o tempo despendido pelo contribuinte. A NF-e é transmitida para a Sefaz da Unidade Federada de embarque das mercadorias (PEREIRA, 2019).

A aprovação de recebimento do destinatário pode ser desenvolvida manualmente no site da Sefaz, por meio do controle de acesso ou, de maneira eletrônica, por meio da "web service" (TRETER et al., 2018). Percebe-se que se trata de um processo quase exclusivamente eletrônico, caracterizando-se, assim, uma operação rápida.

RC: 100828

Disponível em: https://www.nucleodoconhecimento.com.br/contabilidade/preenchimentocorreto 


\subsection{BENEFÍCIOS ESPERADOS COM A NF-e}

A NF-e é o apontamento enunciado e guardado de modo eletrônico com alcance nacional, que acarreta benefícios não apenas para as empresas, mas ainda para o governo e a sociedade (COSTA, 2020).

\subsubsection{PARA EMPRESAS}

As vantagens para os emissores da NF-e são: diminuição de custos de impressão, diminuição de gastos com aquisição de papel, diminuição de custos de envio do documento fiscal, diminuição de custos para guardar documentos fiscais, facilitação de obrigações acessórias, como dispensa de AIDF, diminuição de tempo de parada de caminhões em Postos Fiscais de Fronteira e estímulo ao emprego de relacionamentos eletrônicos com clientes (B2B) (COSTA, 2020). Os sistemas das empresas precisam se ajustar à nova exigência. Em compensação, a implantação da NF-e oferece muitos benefícios. A diminuição de impressão, compra de papel, envio de documentos fiscais e armazenagem é, claramente, uma economia para a organização.

Não é mais preciso solicitar formulários contínuos às gráficas e não é mais preciso ter impressoras matriciais. É, ainda, eliminado o arquivo dos papéis, pois, com a NFe, as notas são armazenadas eletronicamente. $O$ envio do documento fiscal pode ser feito pelo correio eletrônico, apenas imprimindo o DANFE para transitar com a mercadoria e a impressão se dará em somente uma via e em qualquer papel, menos papel jornal. O melhoramento da facilitação de obrigações acessórias da NF-e refere-se a dispensa da AIDF. Entretanto, no projeto SPED, como um todo, foram eliminadas outras obrigações. Com o SPED Fiscal e SPED Contábil, aparecem mudanças nas declarações, substituindo a entrega da declaração federal, como o

RC: 100828

Disponível em: https://www.nucleodoconhecimento.com.br/contabilidade/preenchimentocorreto 
SINTEGRA, e dispensando a impressão de livros fiscais e contábeis, sendo trocados por arquivos digitais (PEREIRA, 2019).

Com a NF-e, considerando o cenário aqui apresentado relacionado a sua implantação, tem-se a diminuição de tempo nas paradas dos veículos de cargas nas unidades de fiscalização, já que as notas têm o mesmo modelo, independentemente da empresa, modificando somente o formato vertical ou horizontal. O modelo e os dados das notas estão preenchidos e situados no mesmo campo para todas as organizações. Além disso, deve-se levar em consideração o fato de que, em todas as notas, está impressa a chave de acesso, o que possibilita à fiscalização consultar através de leitor de código de barras.Com a NF-e espera-se reduzir o tempo para que esta relação seja verdadeiramente incitada pelo uso de moldes acessíveis de comunicação, internet e pela segurança originada pela certificação digital (APARECIDO, 2021).

\subsubsection{PARA O GOVERNO}

Os benefícios relacionados ao processo de implantação da NF-e, no que se refere ao trabalho da fiscalização, bem como à própria percepção dos fiscais são os seguintes: obtenção de um aumento significativo na credibilidade da Nota Fiscal; melhoramento no procedimento de controle fiscal, permitindo uma troca melhor e repartição de dados entre os fiscos; e ajuda aos projetos de escrituração eletrônica contábil e fiscal da Secretaria da Receita Federal do Brasil (VIEIRA; MEDEIROS, 2017). O aumento da confiabilidade acontece pela autorização da nota fiscal de maneira automática e em tempo real, reduzindo, ainda, a burocracia que abrange o relacionamento entre o fisco e o contribuinte. Com a NF-e cada nota faturada pode ser visualizada online no sítio eletrônico da NF-e, prontamente após a autorização (BONFIM et al., 2012).

RC: 100828

Disponível em: https://www.nucleodoconhecimento.com.br/contabilidade/preenchimentocorreto 
Desta forma, acarretará outros benefícios como: a melhoria no controle das transações de venda e transporte, já que, tendo a nota fiscal em tempo real, pode-se consultá-la a qualquer momento. A nota não precisa chegar junto com a mercadoria ao destinatário, pois esta é entregue inicialmente pelo correio eletrônico ao cliente, havendo, portanto, um intercâmbio direto com o emissor, cliente e fisco (SILVA et al., 2014). Destaca-se que o envio da NF-e também inibe a prática de fraudes fiscais. Antes, a nota fiscal era emitida em quatro vias carbonadas, o que facilitava adulterações nas vias. Porém, com a NF-e em via única, dificulta-se esta prática, o que leva à redução da sonegação e o efeito do avanço da arrecadação. A redução da contribuição de impostos deriva da falta de melhoria nos serviços públicos proporcionados pelo Estado (ALBUQUERQUE FILHO; LOPES, 2021).

\subsubsection{PARA A SOCIEDADE}

A NF-e, além dos benefícios para os emissores e ao governo, também leva benefícios à sociedade, como: diminuição do consumo de papel, com resultado positivo ao meio ambiente; estímulo ao comércio no meio eletrônico e ao emprego de novas tecnologias; uniformização das relações eletrônicas entre organizações; e aparecimento de chances de negócios e empregos na prestação de serviços pautados à NF-e (BICCA; MONSER, 2020; MARIANO; AZEVEDO, 2013). Verifica-se que a principal vantagem para a sociedade é a diminuição de gastos com papel, pois o papel leva aproximadamente três meses para se degradar. Além do tempo para a decomposição, o uso do papel colabora com a devastação das árvores, sua principal matéria-prima.

As árvores cooperam para a renovação do oxigênio, por meio de sua fotossíntese. Avaliando o melhoramento como forma de conveniência de novos negócios para a sociedade, vê-se a necessidade de pessoas capacitadas. A NF-e é o subprojeto SPED e, nesse processo, torna-se vantajosa, pois apenas precisa de pessoas que

RC: 100828

Disponível em: https://www.nucleodoconhecimento.com.br/contabilidade/preenchimentocorreto 
tenham desenvoltura de compreensão para de tal modo repassar conhecimentos técnicos aos demais interessados, como empresários e aos cidadãos da comunidade (ANDRADE; MEHLECKE, 2020). Surgem, deste modo, novos campos de trabalho de âmbito contábil e tributário, como consultoria e especializações em novos sistemas eletrônicos para aprimorar a técnica e melhorar os sistemas contábeis e empresariais.

\section{METODOLOGIA}

\subsection{PROCEDIMENTOS METODOLÓGICOS}

Segundo Mazucato (2018), os procedimentos metodológicos lidam com os métodos para se chegar a um estudo final. Trata-se do processo de condução da pesquisa ou um grupo de regras para ensino de ciência e arte. Para elaboração deste estudo, foram desenvolvidas pesquisas por meio de leis, manuais e artigos de revistas, coletados entre os meses janeiro e fevereiro deste ano, utilizando tais palavraschave: fraudes fiscais, nota fiscal eletrônica, NF-e, contabilidade; nos idiomas inglês e português; para identificar as principais falhas das pequenas e médias empresas do setor de comércio, na implantação da NF-e.

Originou-se, com tais cuidados metodológicos, bem como com o emprego das técnicas e ferramentas corretas, respeitando as necessidades de uma pesquisa caracterizada como bibliográfica, dados concisos sobre a temática pesquisada. $\mathrm{O}$ critério de inclusão da pesquisa foi artigos com o recorte temporal de 10 anos. Após a coleta de dados oriundos da pesquisa bibliográfica, foi desenvolvida uma análise minuciosa com cada informação para alcançar o objetivo erguido no decorrer desta pesquisa e, em seguida, as informações serão selecionadas e discutidas no desenvolvimento do estudo.

RC: 100828

Disponível em: https://www.nucleodoconhecimento.com.br/contabilidade/preenchimento$\underline{\text { correto }}$ 


\subsubsection{QUANTO À NATUREZA}

Em relação à natureza do estudo, esta pesquisa caracteriza-se como qualitativa porque, conforme Lira (2019), este tipo de estudo tem o ambiente natural como fonte direta dos dados, buscando o sentido nos fenômenos e processos sociais, não tendo como foco o debate de informações numéricas.

\subsubsection{QUANTO AOS FINS}

Caracteriza-se, quanto aos fins, como uma pesquisa descritiva, pois expõe as particularidades de um fenômeno ou experimento para o estudo desenvolvido. Neste tipo de pesquisa, tem-se um estudo detalhado, com coleta, análise e interpretação de dados, não havendo envolvimento do pesquisador no estudo (LAKATOS; MARCONI, 2010).

\subsubsection{QUANTO AOS MEIOS}

Quanto aos meios, tem-se uma pesquisa bibliográfica por esclarecer um problema a partir da literatura publicada em meios virtuais. É necessária para se ter conhecimento e analisar o assunto, levantando dados para munir o pesquisador de conhecimentos necessários para a elaboração do estudo. Conforme Marconi e Lakatos (2011), trata-se de um levantamento de bibliografia já existente, processo este que se dá por meio de livros, periódicos de revistas, dissertações e publicações avulsas, com a intenção de implantar o pesquisador na referida temática.

\section{CONSIDERAÇÕES FINAIS}

Este artigo teve como objetivo compreender a importância do preenchimento correto da Nota Fiscal Eletrônica (NF-e) na fluência de informações entre as partes envolvidas do processo de empresas de pequeno e médio porte no setor do

RC: 100828

Disponível em: https://www.nucleodoconhecimento.com.br/contabilidade/preenchimentocorreto 
comércio, apresentando a importância da NF-e para o planejamento da empresa e os impactos de sua implantação, demonstrando a necessidade de detectar e impedir falhas no preenchimento da NF-e, bem como identificou-se os principais entraves encontrados pelas empresas de pequeno e médio porte no que diz respeito à implantação da NF-e. O estudo buscou evidenciar a importância das tecnologias para o dia a dia das empresas, pois, com o passar do tempo e com o avanço das tecnologias, a contabilidade não ficou para trás, evoluiu bastante e, hoje, estamos vivendo a era da informação, a era do Sped.

A evolução dos processos e controles não teria sido possível sem que houvesse inovações nesta área. Um dos desdobramentos do projeto Sped é a Nota Fiscal Eletrônica. Contudo, este estudo demonstrou que um dos erros mais comuns na emissão de Notas Fiscais eletrônicas está no preenchimento incorreto do documento e, por isso, o assunto tratado nesta pesquisa é de grande colaboração para evitar incômodos com o fisco. O grande destaque do artigo foi responder à questão norteadora: Como é possível evitar transtornos relacionados ao preenchimento incorreto de Nota Fiscal Eletrônica em empresas de pequeno e médio porte do setor do comércio? Foi possível constatar que a grande verdade é que, por se tratar de um processo trabalhoso, preencher todos os dados pode ocasionar vários problemas na emissão da NF-e, seja por falha de digitação, esquecimento ou erro no próprio sistema das prefeituras.

Assim, para que não se tenha grandes problemas, é interessante que a empresa tenha um sistema de emissão de NF-e que automatize de maneira inteligente este trabalho, impedindo, assim, a falha humana. Com esses cuidados, a tecnologia torna-se benéfica, assegurando, dessa forma, a partir dos responsáveis, todo o suporte que a empresa necessita. Concluiu-se por meio da pesquisa bibliográfica que o preenchimento incorreto de uma informação na nota fiscal eletrônica pode ocasionar muitos transtornos à empresa, pois, além do cliente não aceitar a nota

RC: 100828

Disponível em: https://www.nucleodoconhecimento.com.br/contabilidade/preenchimentocorreto 
fiscal e a empresa correr o risco de não conseguir o cancelamento deste documento, existe a possibilidade de a empresa ser autuada em uma eventual fiscalização.

\section{REFERÊNCIAS}

AGUIAR, G.; GOUVEIA, L. B. O Programa de Benefícios Fiscais da nota Fiscal Eletrônica como Estímulo à Cidadania Fiscal. In: 26th APDR Congress. Evidencebased territorial policymaking: formulation, implementation and evaluation of policy, 2019.

ALBUQUERQUE FILHO, A. R.; LOPES, F. J. R. Benefícios e dificuldades a partir da implementação do SPED: um estudo com profissionais de contabilidade. Navus: Revista de Gestão e Tecnologia, v. 11, n. 1, p. 1-15, 2021.

ALENCAR, L. C.; FRANÇA, A. A. Contabilidade e Tecnologia: Um Estudo Bibliométrico na Scientific Electronic Library Online (2001-2019)/Accounting and Technology: A Bibliometric Study at Scientific Electronic Library Online (20012019). ID on line REVISTA DE PSICOLOGIA, v. 14, n. 50, p. 83-95, 2020.

ALMEIDA, L.; RIBEIRO, N. T.; BIANCOLINO, C. A. Gestão estratégica dos sistemas transacionais (ERP) na perspectiva de pós-implementação: Modelagem de competências de tecnologia da informação em organizações de saúde no âmbito hospitalar. International Journal of Health Management Review, v. 2, n. 2, p. 91108, 2016.

AMORIM, F. B.; TOMAÉL, M. I. Gestão da informação e gestão do conhecimento na prática organizacional: análise de estudos de casos. $\mathbf{R D B C l}$ : Revista Digital de Biblioteconomia e Ciência da Informação, v. 9, n. 1, p. 1-22, 2011.

ANDRADE, C. B. H.; MEHLECKE, Q. T. C. As inovações tecnológicas e a contabilidade digital: um estudo de caso sobre a aceitação da contabilidade digital RC: 100828

Disponível em: https://www.nucleodoconhecimento.com.br/contabilidade/preenchimentocorreto 
no processo de geração de informação contábil em um escritório contábil do Vale do Paranhana/RS. Revista Eletrônica de Ciências Contábeis, v. 9, n. 1, p. 93-122, 2020.

ANZILAGO, M.; ZANIN, D. F.; BEZERRA, C. A. Vantagem competitiva na utilização de sistemas de informação: Enterprise Resource Planning-ERP. In: XI Congresso da Associação Nacional de Programas de Pós-Graduação em Ciências Contábeis, 2017.

APARECIDO, J. P. A implantação e os benefícios dos documentos eletrônicos Pós SPED. Revista de Estudos Interdisciplinares do Vale do Araguaia-REIVA, v. 4, n. 01 , p. 23-23, 2021.

AZEVEDO, O. R.; MARIANO, P. A. SPED Sistema Público de Escrituração Digital. 6ª ed. São Paulo: IOB, 2014.

BARBARIOLE, L. F. et al. O impacto da implantação da nota fiscal eletrônica na gestão das empresas atacadistas no estado do Espírito Santo. In: Anais do Congresso Brasileiro de Custos-ABC, 2010.

BATISTA, G. P. et al. Escrituração Contábil Digital nas Empresas Tributadas pelo Lucro Real. Revista Eletrônica do Departamento de Ciências Contábeis \& Departamento de Atuária e Métodos Quantitativos (REDECA), v. 4, n. 2, p. 97112, 2017.

BELLUZZO, R. C. B. Bases teóricas de gestão da informação: das origens aos desafios na sociedade contemporânea. Palabra Clave (La Plata), v. 7, n. 1, 2017.

BICCA, D.; MONSER, N. T. B. Tecnologia aplicada à contabilidade: estudo de caso em uma organização contábil. RECONF-Revista Contabilidade em Foco, v. 2, n. 2, p. 4-31, 2020.

RC: 100828

Disponível em: https://www.nucleodoconhecimento.com.br/contabilidade/preenchimento$\underline{\text { correto }}$ 
BONFIM, D. P. et al. Nota fiscal eletrônica: uma mudança de paradigma sob a perspectiva do fisco estadual. ConTexto, v. 12, n. 21, p. 17-28, 2012.

BRASIL. Lei 10.406, de 10 de janeiro de 2002. Institui o Código Civil. Diário Oficial [da] República Federativa do Brasil. Brasília, DF, 10 jan. 2002.

BRASIL. Lei 11.101, de 09 de fevereiro de 2005. Regula a recuperação judicial, a extrajudicial e a falência do empresário e da sociedade empresária. Diário Oficial [da] República Federativa do Brasil, Brasília, DF, 10 fev. 2005.

BUfREM, L. S.; SILVEIRA, M.; FREITAS, J. L. Políticas de Ciência, Tecnologia e Inovação no Brasil: panorama histórico e contemporâneo. P2P E INOVAÇÃO, v. 5, n. 1 , p. $6-25,2018$.

CÂNDIDO, A. C. Gestão da informação e inovação aberta: oportunidades em ações integradas. Brazilian Journal of Information Science: research trends, v. 11, n. 2, 2017.

DIEGUES, A. C. et al. Economia da ciência, tecnologia e inovação: fundamentos teóricos e a economia global. Revista Brasileira de Inovação, v. 18, n. 1, p. 205210, 2019.

FERNANDES, R. B. et al. Impacto da utilização de sistemas de ERP em dimensões estratégicas de pequenas e médias empresas. Exacta, v. 15, n. 1, p. 57-74, 2017.

GAZZOLA, S. B.; WOIDA, L. M. Cultura informacional como alicerce da gestão da informação contábil. In: ENANCIB 2019, 2019.

ITG 2000 (R1) - Interpretação Técnica Geral. Interpretação Técnica Geral - ITG 2000 (R1) - Escrituração contábil, de 23 de março de 2011. 2011. Disponível em: 
http://www1.cfc.org.br/sisweb/sre/detalhes_sre.aspx?Codigo=2011/001330. Acesso em: 19 jul. 2021.

LAKATOS, E. M.; MARCONI, M. de. A. Fundamentos de Metodologia científica. $7^{a}$ ed. São Paulo: Atlas, 2010.

LIRA, B. C. Passo a passo do trabalho científico. São Paulo: Editora Vozes, 2019.

MACHADO, J. et al. A proteção de dados pessoais nos programas de Nota Fiscal: um estudo de caso do "Nota Fiscal paulista"| Protection of personal data in programs for tax-evasion prevention by collecting invoices: the case of São Paulo. Liinc em Revista, v. 12, n. 2, 2016.

MAZUCATO, T. Metodologia da pesquisa e do trabalho científico. Penápolis: FUNEPE, 2018.

MONTEIRO, S. A.; DUARTE, E. N. Bases teóricas da gestão da informação: Da gênese às relações interdisciplinares. InCID: Revista de Ciência da Informação e Documentação, v. 9, n. 2, p. 89-106, 2018.

NOGUEIRA, M. O.; ZUCOLOTO, G. F. Um pirilampo no porão: um pouco de luz nos dilemas da produtividade das pequenas empresas e da informalidade no Brasil. Brasília: Ipea, 2017.

OLIVEIRA, G. P. Contabilidade Tributária. $3^{\underline{a}}$ ed rev. e atualizada. São Paulo: Saraiva, 2009.

ORIGUELA, L. A. Os Principais Impactos do SPED na Profissão Contábil: Uma Análise da Percepção dos Profissionais de Contabilidade. Caderno Profissional de Administração da UNIMEP, v. 7, n. 1, p. 45-62, 2017.

RC: 100828

Disponível em: https://www.nucleodoconhecimento.com.br/contabilidade/preenchimentocorreto 
OTTONICAR, S. L. C.; SANTOS, B. R. P. dos.; MORAES, I. S. de. Aplicabilidade da Competência em Informação e da Organização do Conhecimento no processo de Gestão da Informação. RDBCl: Revista Digital de Biblioteconomia e Ciência da Informação, v. 15, n. 3, p. 629, 2017.

PARISOTTO, C.; FREIRE, A. Nota fiscal eletrônica-desenvolvendo e implantando um módulo emissor nf-e. Revista Ceciliana, 2010.

PEREIRA, S. A. Governança Eletrônica Na Administração Pública: Estudo de caso sobre a Nota Fiscal Eletrônica-NF-e. Revista Razão Contábil \& Finanças, v. 5, n. $1,2019$.

RODRIGUES, C.; BLATTMANN, U. Gestão da informação e a importância do uso de fontes de informação para geração de conhecimento. Perspectivas em Ciência da Informação, v. 19, p. 4-29, 2014.

RODRIGUES, J. R. M. C.; JACINTO, M. DA S. Escrituração contábil digital, a transparência das informações e o perfil do profissional contábil. Revista Hum@ nae, v. 5, n. 1, 2011.

RUSCHEL, M. E.; FREZZA, R.; UTZIG, M. J. S. O impacto do SPED na contabilidade desafios e perspectivas do profissional contábil. Revista Catarinense da Ciência Contábil, v. 10, n. 29, p. 09-26, 2011.

SANTOS, C. D.; VALENTIM, M. L. P. As interconexões entre a gestão da informação e a gestão do conhecimento para 0 gerenciamento dos fluxos informacionais. Perspectivas em gestão \& conhecimento, p. 19-33, 2014.

SEBRAE - SEBRAE-NA/ Dieese. Anuário do trabalho no micro e pequena empresa. $2013 . \quad$ Disponível em:

RC: 100828

Disponível em: https://www.nucleodoconhecimento.com.br/contabilidade/preenchimento$\underline{\text { correto }}$ 
www.sebrae.com.br/Sebrae/Portal\%20Sebrae/Anexos/Anuario\%20do\%20Trabalho\% 20Na\%20Micro\%20e\%20Pequena\%20Empresa_2013.pdf. Acesso em: 20 set 2021.

SENA, P. M. B.; VIANNA, W. B.; BLATTMANN, U. Aproximações conceituais entre informação, tecnologia e inovação no contexto das startups: desafios interdisciplinares para Ciência da Informação. RDBCl: Revista Digital de Biblioteconomia e Ciência da Informação, v. 17, p. e019002-e019002, 2019.

SILVA, L. C. et al. Os impactos da nota fiscal eletrônica nas microempresas e empresas de pequeno porte sediadas em Umuarama/PR. Navus-Revista de Gestão e Tecnologia, v. 4, n. 1, p. 49-63, 2014.

SOUZA, E. D. de.; DIAS, E. J. W.; NASSIF, M. E. A gestão da informação e do conhecimento na ciência da informação: perspectivas teóricas e práticas organizacionais. Informação e Sociedade: estudos, v. 21, n. 1, p. 55-70, 2011.

TOMELIN, I. P.; NOVAES, J. B. V.; BUCKER, P. P. A contabilidade na era digital: escrituração contábil digital. Revista de Ciências Gerenciais, v. 14, n. 19, p. 249268, 2010.

TRETER, J.; GONÇALVES, A. L.; PORCIUNCULA, L. Nota fiscal eletrônica na rotina dos clientes de um escritório contábil-uma experiência desafiadora. CataventosRevista de Extensão da Universidade de Cruz Alta, v. 10, n. 1, p. 33-54, 2018.

VIEIRA, G. C. da. S.; MEDEIROS, S. Os benefícios da nota fiscal eletrônica nos postos de combustível de Porto Velho - RO. Setor: Zona Leste. In: Centro Universitário São Lucas, 2017.

VIEIRA, P. A. et al. Efeitos do programa de Nota Fiscal eletrônica sobre o aumento da arrecadação do Estado. Revista de Administração Pública, v. 53, p. 481-491, 2019.

RC: 100828

Disponível em: https://www.nucleodoconhecimento.com.br/contabilidade/preenchimentocorreto 
Enviado: Outubro, 2021.

Aprovado: Novembro, 2021.

RC: 100828

Disponível em: https://www.nucleodoconhecimento.com.br/contabilidade/preenchimentocorreto 